\title{
Responsabilidade Social e Defesa dos Direitos Humanos: O Debate Sobre a Atuação das Empresas Transnacionais
}

\author{
Patrícia Mara Cabral de Vasconcellos \\ Doutora em Relações Internacionais pela Universidade de Brasília. Professora-adjunta do Departamento de Ciências \\ Sociais da Universidade Federal de Rondônia (Unir). Professora permanente no Programa de Pós-Graduação \\ Mestrado Profissional Interdisciplinar em Direitos Humanos e Desenvolvimento da Justiça (Dhjus/Unir). Líder do \\ Grupo de Pesquisa Centro de Estudos em Fronteiras Amazônicas e Desigualdades Sociais. Pesquisadora da Rede de \\ Pesquisa em Política Externa e Regionalismo (Repri). http://lattes.cnpq.br/3571585131621064. \\ https://orcid.org/0000-0002-9077-8734. pvasconcellos@unir.br
}

O artigo analisa como a atuação das empresas transnacionais é questionada nas organizações internacionais, desde a década de 90 e, em especial, de que maneira, a partir da Resolução 26/9 de 2014 da Organização das Nações Unidas, tem-se buscado um tratado vinculante para responsabilizá-las nos casos de violações dos direitos humanos. Assim, inicialmente, a discussão demarca conceitos como a responsabilidade social corporativa, na expectativa social de uma conduta ética voluntária por parte das corporações. Com a recorrência da violação de direitos, no entanto, o debate passou a incorporar a defesa dos direitos humanos e a reivindicação de normas internacionais de responsabilização. Para a análise, a metodologia constitui-se de pesquisa bibliográfica, documental e estudo de caso. Conclui-se que as diretrizes da ONU sobre a temática inserem-se em um sistema internacional assimétrico, de governos nacionais fragilizados. Apesar das transformações no debate, as diretrizes são insuficientes para frear a impunidade e converter a fragilidade jurídica da população ante o poder corporativo.

Palavras-chave: Empresas transnacionais. Direitos humanos. Nações Unidas. Responsabilidade social.

\section{SOCIAL RESPONSIBILITY AND DEFENSE OF HUMAN RIGHTS: THE DEBATE ON THE ACTIVITIES OF TRANSNATIONAL CORPORATIONS}

\section{ABSTRACT}

This article analyzes how the activities of transnational corporations have been questioned by international organizations since the 1990s and how, in particular, based on Resolution 26/9 of 2014 of the United Nations Organization, a binding treaty is considered to hold corporations accountable for cases of human rights violations. The discussion begins by highlighting concepts such as corporate social responsibility. At this moment, there is the expectation of a voluntary ethical conduct of corporations. However, given recurring rights violations, the debate has begun to incorporate the defense of human rights and society's claims to create international norms of accountability. The methodology constituted bibliographical, documentary research and case study. The conclusion suggests that the UN guidelines on the subject fall within an asymmetric international system of fragile national governments. Despite the transformations in the debate, these guidelines are consequently insufficient to prevent impunity and protect populations from corporate power.

Keywords: Transnational corporations. Human rights. United Nations. Social responsibility.

SUMÁRIO

1 Introdução. 2 A conduta das transnacionais e o anseio por responsabilidade social. 3 A linguagem dos direitos humanos e a expectativa por justiça. 4 Considerações finais. 5 Referências.

Recebido em: 15/9/2019

Aceito em: 2/10/2019 


\section{INTRODUÇÃO}

A globalização da economia e a atuação das empresas transnacionais provocaram impactos na função do Estado e nas demandas da sociedade. Neste cenário, as transnacionais tornaram-se fonte de poder, por vezes protagonistas em determinada área político-decisória, deslocando, inclusive, o poder do Estado. Para mensurar o poder corporativo, Maso (2017) cita que na atualidade tem-se "737 grupos econômicos que controlam $80 \%$ do mundo corporativo; destes, 147 controlam 40\%, sendo que 3/4 são instituições financeiras" (p. 21).

Se, por um lado, as transnacionais assumiram um papel relevante na governança global e estabeleceram uma relação com o Estado amparada no discurso do desenvolvimento, por outro há casos como o Edifício Rana Plaza, ${ }^{1}$ em Bangladesh, e a contaminação da região amazônica causada pela Chevron-Texaco, ${ }^{2}$ que são marcos na luta pela proteção dos direitos humanos contra a atuação das transnacionais. Tais casos foram citados no discurso de abertura do terceiro período de sessões do Conselho de Direitos Humanos (CDH), ${ }^{3}$ pela ministra de Relações Exteriores do Equador, Maria Fernanda Espinosa Garcés, ao destacar a proposição de um tratado com obrigações jurídicas internacionais para evitar que desastres deste tipo se repitam (HRC, 2018). Assim, a nova realidade mundial despertou a necessidade de um processo de governança que discutisse os impactos positivos e, também, as perturbações sociais derivadas da conduta das corporações.

A literatura sobre as transnacionais é profusa e aborda temáticas como o papel das corporações no sistema capitalista (VERNON, 1980; DOS SANTOS, 2000), o processo de internacionalização com foco administrativo e organizacional (DUNNING, 1995; CAVES, 1995) ou como eixo de política externa (GILPIN, 1975; STRANGE, 1988), além de publicações produzidas pelo Banco Mundial, pela Organização para a Cooperação e Desenvolvimento Econômico (Ocde) e pela Organização das Nações Unidas (ONU). Apesar do amplo espectro, é importante sistematizar e promover uma análise político-histórica sobre os debates conduzidos pela ONU diante dos impactos negativos da atuação das Empresas Transnacionais (ETs). Assim, o objetivo do artigo é compreender como os questionamentos e expectativas sociais sobre a conduta das transnacionais transformam-se ao longo das décadas, desde 1990 até a atualidade, na ONU. A inquietação social revela-se na pergunta: Como impedir os danos recorrentes causados pelas ETs? A hipótese é que a pressão e as diretrizes fornecidas pela Organização Internacional oficializam os anseios sociais, mas atuam de modo insuficiente para alterar os sistemas de justiça.

\footnotetext{
Em abril de 2013 ocorreu o desabamento do Edifício Rana Plaza. No local funcionavam fábricas de tecidos com desrespeito às medidas de segurança, desde o comprometimento das condições estruturais à ausência de saídas de emergências, além das condições precárias de trabalho. Marcas de roupas mundialmente conhecidas atuavam no local, tais como GAP, H\&M, Walmart, Targ, Adidas, Benetton, entre outras. No desastre, mais de mil pessoas morreram e mais de duas mil ficaram feridas.

2 As operações da Chevron, na Amazônia norte do Equador, causaram a poluição de 480 mil hectares da floresta amazônica equatoriana por meio do despejo de mais de 16 bilhões de litros de água tóxica e pela formação de piscinas de resíduos contaminantes próximas aos poços de petróleo perfurados e às fontes de água. Aproximadamente 30 mil indígenas e camponeses reunidos na União de Afetados pelas Operações da Texaco (UDAPT) movem uma ação de reparação de danos contra a empresa desde 1993. Ver: Mendoza, Pablo Fajardo. Vazio Jurídico e abuso corporativo: caso Chevron. In: Transnacionais e Direitos Humanos. América Latina, 520, Ed. português, jan. 2017.

3 O terceiro período de sessões do Conselho de Direitos Humanos ocorreu de 23 a 27 de outubro de 2017.
} 


\section{Humanos e}

Democracia

Assim, no primeiro momento, percebe-se que os termos do debate abordam a função política social pública das ETs. Posteriormente, a discussão incorpora a linguagem dos direitos humanos, instaurando a demanda, no Conselho de Direitos Humanos da ONU, por um tratado vinculante com normas de responsabilização, ou seja, a Resolução 26/9 de 26 de junho de 2014.

Para a metodologia adota-se a pesquisa bibliográfica e documental. Dada a amplitude do tema, utilizam-se, como fonte primária, relatórios e resoluções produzidos pela Organização das Nações Unidas. Dentre os inúmeros casos de violações de direitos humanos cometidas pelas transnacionais, para além dos casos citados nos próprios documentos da ONU, primou-se por avaliar a argumentação teórica por meio de estudo de caso. Optou-se pela atuação das empresas transnacionais brasileiras na área de construção, em especial a Odebrecht. Dessa forma, metodologicamente verifica-se em que medida a teoria abarca o fenômeno na realidade (GEORGE; BENNETT, 2004).

O artigo está dividido em duas partes. Na primeira, após uma breve apresentação do conceito de empresas transnacionais, visa-se a esclarecer como o debate surge na década de 90 do século 20, preconizado por normas de responsabilidade social corporativa (RSC). 0 documento base é o "The social responsibility of transnational corporations", elaborado no âmbito da Conferência das Nações Unidas sobre Comércio e Desenvolvimento. A análise da literatura mostra que as diretrizes de responsabilidade social são uma tentativa de minimizar ou corrigir os impactos negativos da atuação das ETs. Ao longo do tempo, no entanto, foram ditas como ineficazes. No caso da Odebrecht, demonstra-se a iniciativa da empresa na década de 90 em incorporar as diretrizes da RSC.

$\mathrm{Na}$ segunda parte, assinala-se como a sociedade civil mobilizou-se para reivindicar na Organização das Nações Unidas um tratado vinculante para impor obrigações internacionais às corporações. Assim, o discurso, a partir dos anos 2000, incorpora a esfera dos direitos humanos para requerer, mais do que um padrão de conduta das transnacionais, uma reformulação do direito internacional. Os documentos de referência são: "Guiding Principles on Businesses and Human Rights" e "Elaboration of an international legally binding instrument on transnational corporations and other business enterprises with respect to human rights", elaborados pelo Escritório do Alto Comissariado das Nações Unidas para os Direitos Humanos e pelo Conselho de Direitos Humanos da ONU, respectivamente. No Brasil, as obras recentes da construtora Odebrecht, como a usina hidrelétrica de Santo Antônio (RO) e Belo Monte (PA), dentre outras, revelam a reincidência em violações de direitos humanos.

Em conclusão, visualiza-se uma lacuna de governança em um sistema internacional assimétrico e de governos nacionais fragilizados, em que as demandas por desenvolvimento estão sujeitas à impunidade, vulnerabilidade e violação de direitos fundamentais. A reparação tem expressado a desigualdade de forças (poder econômico e político, mas, também, jurídico) da população ante as transnacionais, o que é evidenciado, inclusive, no caso brasileiro. Apesar da expectativa por formas de controle sobre a atuação das ETs nas organizações internacionais, ainda não há uma norma, tribunal ou diretriz, ou seja, um poder capaz de igualar a correlação de forças entre indivíduos e empresas. 


\section{A CONDUTA DAS TRANSNACIONAIS E O ANSEIO POR RESPONSABILIDADE SOCIAL}

Quando se trata de empresas com atuação no exterior, diversos conceitos tentam apreender seus significados, dentre eles os de empresas multinacionais, transnacionais, internacionais ou empresas globais (MERLE, 1981). O termo multinacional, por exemplo, teria sido utilizado pela primeira vez por David E. Lilienthal, em conferência pronunciada em abril de 1960 no Carnegie Institute of Technology, em trabalho denominado The Multinational Corporation (LILIENTHAL, 1960). Desde aquele momento, em geral, cada um dos termos apresentados enfatiza uma determinada característica, seja a divisão internacional da produção ou mesmo a possibilidade de atuar em operações globais, como as corporações financeiras.

Segundo a Conferência das Nações Unidas sobre Comércio e Desenvolvimento (UNCTAD), contudo, as empresas transnacionais são assim definidas:

Corporações transnacionais (TNCs) são empresas incorporadas ou não incorporadas que incluem a empresa matriz e suas afiliadas estrangeiras. A empresa matriz é definida como uma empresa que controla ativos de outras entidades em outros países que não o seu país de origem, geralmente por possuir certa participação acionária no capital (Tradução nossa) ${ }^{4}$ (UNCTAD, 2012).

De toda forma, a atuação empresarial além fronteiras, de forma sistemática e com grande mobilidade de capital, retrata uma transformação na relação Estado-empresa que, nas décadas de 60 a 80 do século 20, contextualiza-se pela presença das multinacionais dos países do Norte nos países ditos subdesenvolvidos (Sul). Nesta conjuntura, diversos autores interpretaram as multinacionais como reprodutoras das relações de exploração e dependência (HYMER, 1983; MARINI, 1973-2005; PREBISCH, 1964). O ponto central do debate eram as dúvidas sobre a capacidade que o Estado e a sociedade civil teriam para garantir os seus interesses ante o poder econômico das multinacionais. Em outras palavras, questiona-se em que medida as empresas transnacionais poderiam ser prejudiciais aos países em desenvolvimento.

Frutos do capitalismo globalizado, as ETs refletem os resultados da expansão econômica (lucro) e da capacidade produtiva mundial. Pela própria dinâmica de correlação de forças (Estado-empresa), no entanto, buscam atuar em países com flexibilidade ou fragilidade nas normas, o que acarreta impactos negativos desde a precarização das relações de trabalho, a influência na política externa e a ocorrência de danos ambientais. Oculto na definição conceitual, deve-se compreender que as ETs possuem fluidez na territorialidade, nacionalidade e alta concentração de capital. Todas são características que dificultam o exercício da soberania nacional e dos sistemas de justiça.

Assim, em um primeiro momento, as organizações internacionais abordaram o tema no intuito de mensurar a esfera de poder das empresas e instituir códigos de conduta. Segundo Merle (1981), em 1973 a matéria foi debatida na Organização Internacional do Trabalho (OIT) e no Conselho Econômico e Social da ONU. Em 1976 foi deliberada pela Organização para a

\footnotetext{
Transnational corporations (TNCS) are incorporated or unincorporated enterprises comprising parent enterprises and their foreign affiliates. A parent enterprise is defined as an enterprise that controls assets of other entities in countries other than its home country, usually by owning a certain equity capital stake (UNCTAD, 2012).
} 


\section{Humanos e \\ Democracia}

Cooperação e Desenvolvimento Econômico (Ocde), resultando nas Diretrizes para as Empresas Multinacionais. ${ }^{5}$ Em 1977 teve-se a Declaração Tripartite de Princípios sobre as Empresas Multinacionais e a Política Social ${ }^{6}$ da OIT.

Na década de 90, o caso da Nike ilustra os termos do problema e desafios. No período, a empresa sofreu diversas denúncias que abalaram a sua imagem empresarial. Como modo de gestão da produção, a Nike terceirizava o processo de confecção de seu produto em fábricas no Japão (anos 1970), Coreia do Sul e Taiwan (anos 1980) e Indonésia (anos 1990). Na Indonésia, por exemplo, ativistas em direitos humanos denunciaram os baixos salários (menos de 1 dólar por dia) e as precárias condições de trabalho (RUGGIE, 2014; BEZERRA, 2007). Para a Nike, o primeiro desafio foi reconhecer que havia responsabilidade compartilhada entre a empresa e as fábricas que realizavam a produção (cadeias de fornecimento), ou seja, a empresa não poderia se isentar de responsabilidade nos danos ou violações de direitos causados por organizações terceirizadas em qualquer país que fosse. Neste sentido, descortinava-se a relação direta ou indireta da responsabilidade empresarial pelo desenvolvimento social nos países em que exerciam suas atividades. Assim, nos anos 1990 consolida-se uma agenda em que o desenvolvimento inclui os termos da "responsabilidade corporativa" e do "investimento responsável".

De fato, a década de 90 é marcada por movimentos que incentivavam o debate sobre a responsabilidade social, como a discussão sobre o desenvolvimento sustentável realizada pela Comissão Mundial de Meio Ambiente e Desenvolvimento das Nações Unidas, em 1987, e a Conferência das Nações Unidas sobre o Meio Ambiente e o Desenvolvimento (ECO 92). Além da questão ambiental, na agenda do desenvolvimento incorporam-se questões como corrupção, transparência, direitos do trabalho, dentre outras (BEZERRA, 2007). Dessa forma, a preocupação com a responsabilidade social torna-se essencial para a manutenção e conquista de mercado pelas empresas. A partir desse momento, o investimento em responsabilidade social é transformado em valor, ${ }^{7}$ em diferencial no mercado. Criam-se institutos, como a norma SA $8000^{8}$ de 1997, o Pacto Global ${ }^{9}$ (1999) e as Metas do Milênio ${ }^{10}$ (2000), com o objetivo de confluir o fator econômico com as necessidades ambientais e sociais.

\footnotetext{
As Diretrizes foram atualizadas em 2000 e 2011. Ver: https://www.oecd.org/.

A Declaração foi revisada em 2000, 2006 e 2017. Ver: http://www.ilo.org.

O investimento em RSC não compromete a lucratividade da empresa, tendo em vista que tende a aumentar seu capital reputacional, gerando novas oportunidades de negócios.

8 A norma SA 8000 é uma norma internacional de caráter voluntário que trata, em especial, das condições de trabalho baseando-se nas diretrizes da Organização Internacional do Trabalho (OIT) e de convenções das Nações Unidas (ONU). Destaca-se, por meio desta norma, a proibição do trabalho infantil, o cumprimento das leis trabalhistas, a saúde e a segurança no trabalho, entre outros.

9 O Pacto Global foi uma iniciativa do secretário das Nações Unidas Kofi Annan, apresentada no Fórum Econômico Mundial (Fórum de Davos) em 31 de janeiro de 1999. Foi oficialmente lançado em 26 de julho de 2000 no escritório da ONU em Nova York. Trata-se de uma iniciativa voluntária que atualmente reúne aproximadamente 12 mil organizações signatárias. O objetivo do Pacto Global é oferecer diretrizes para uma prática direcionada ao respeito aos direitos humanos e cidadania na área empresarial.

${ }^{10}$ Nos anos 2000 a ONU aprovou o documento denominado "Declaração do Milênio", com oito objetivos (Metas do Milênio) para serem alcançados por seus Estados-membros até o ano de 2015 no intuito de promover o desenvolvimento e erradicar a pobreza no mundo.
} 
Na Organização das Nações Unidas, como relata Feeney (2009), fruto das pressões da sociedade civil, várias foram as tentativas de estabelecer diretrizes sobre a responsabilidade das empresas em casos de atividades ilícitas ou antiéticas. As propostas visavam a regulamentar a atuação das empresas transnacionais ou fornecer um código de conduta para estes agentes econômicos. No contexto apresentado, o conceito de Responsabilidade Social Corporativa (RSC) visou a estabelecer uma diretriz de conduta para as empresas e esclarecer sobre a sua contribuição para o desenvolvimento.

Não havia, contudo, um consenso sobre o conceito de responsabilidade social. As Nações Unidas, em uma tentativa de elucidar os significados do termo, apresenta, no documento "The social responsability of transnational corporations" (UNCTAD, 1999), a diferença entre a responsabilidade social e a filantropia. $O$ documento é importante porque elucida as expectativas com relação à atuação social das corporações e, também, o escopo de suas obrigações. Salienta-se que no início desse debate há dúvidas sobre o que pode ser exigido das empresas e como estas interpretam as demandas sociais.

De modo geral, preceitua-se que a responsabilidade social corporativa deve corresponder a algo além do mínimo exigido por lei, equiparando-se aos princípios éticos e às expectativas sociais, indo além do dever jurídico, sem, contudo, ampliá-lo (UNCTAD, 1999). Em outras palavras, trata-se de uma relação entre empresa e comunidade que ocorre de modo voluntário baseado na ética empresarial.

O documento da UNCTAD (1999) salienta que a filantropia e o mero cumprimento da lei não significam responsabilidade social. A filantropia não é um elemento essencial do negócio e está vinculada com o envolvimento em causas nobres. No caso do cumprimento da lei, trata-se de um requisito mínimo para o funcionamento de qualquer empresa. Assim, a RSC é aquela concebida no comportamento operacional da empresa diante dos impactos causados à sociedade. Para além dos mandatos legais, a RSC ajuda a satisfazer as expectativas da sociedade em que atua, em especial, quando se trata de locais com fragilidade jurídica.

A diferença entre a filantropia e a responsabilidade social é uma questão de grau definida em três fases (UNCTAD, 1999). Na primeira, na qual se enquadra a filantropia, a ação empresarial é motivada por um dever moral de iniciativa do benfeitor. Prerrogativas de caridade e benevolência estão presentes na ação. No segundo estágio, a expectativa que a sociedade possui com relação à empresa torna-se mais forte, e as ações deixam de ter caráter meramente voluntário e humanitário para se constituírem em mandatos judiciais. O não cumprimento da lei pode acarretar normas imperativas e restritivas. A empresa tem o dever de cumprir a lei. Na terceira fase, os laços sociais estão presentes e os padrões de responsabilidade são incorporados à natureza das relações corporativas. Não é simplesmente o respeito a normas jurídicas, ainda que as ações empreendidas possam vir a normatizar-se. É perceber impactos e ver-se como responsável, passando a incorporar a expectativa social e sendo capaz de promover iniciativas para o bem-estar.

Para esclarecer, Peliano (2001, p. 102) apresenta, em seu estudo, um quadro em que sistematiza as características da filantropia e da responsabilidade social. A autora destaca a seguinte diferença: na filantropia a motivação é voluntária, enquanto na responsabilidade social a motivação deriva da consciência de responsabilidade da empresa. Assim, no caso da filantropia, as ações não necessariamente possuem caráter constante. Na responsabilidade 


\section{Humanos e}

Democracia

social, por sua vez, as ações são parte integrante da empresa. Não é mera opção dos dirigentes, mas uma missão institucional, isto é, a ação social é incorporada na cultura da empresa como postura proativa.

Na filantropia não existe a preocupação de vincular a imagem da empresa à ação social, ao contrário da responsabilidade social. Além disso, na ação filantrópica a ação da empresa não se relaciona com as ações do Estado. Por outro lado, na responsabilidade social as ações da empresa, em geral, complementam as ações sociais do Estado, agindo em forma de parceria, partilhando as responsabilidades públicas. ${ }^{11}$

Adicionalmente, Veloso (2005) explica que a RSC é uma ação social que visa a melhorar as condições de vida e de cidadania da população. Salienta-se que as ações devem ser elaboradas, efetivadas ou, ao menos, financiadas pelas empresas. Para Veloso (2005), a dificuldade em estabelecer diretrizes e conceituar processos reside em compreender o fenômeno da privatização do público ou da publicização do privado. Em outras palavras, conseguir perceber como o social pode ser construído por meio de atividades econômicas das empresas.

De toda forma, na RSC as atitudes da empresa têm caráter voluntário. As condutas sugeridas pela ONU, como adotar em suas práticas corporativas os princípios da Declaração dos Direitos Humanos, da Organização Internacional do Trabalho e da Conferência das Nações Unidas sobre o Meio Ambiente e o Desenvolvimento (Rio-92), são facultativas e, portanto, nem sempre são seguidas. A partir desta constatação, surge a pergunta: As normas voluntárias são suficientes para conter e reparar os impactos negativos das transnacionais?

As críticas de movimentos sociais sobre as normas de RSC são de que há uma contradição nas ações empresariais, em que parte da RSC torna-se somente marketing e mascara os interesses empresariais ${ }^{12}$ (PACS, 2015).

Análises promovidas, por exemplo, pelo Instituto Políticas Alternativas para o Cone Sul, partem do pressuposto de que as Diretrizes Internacionais ou Pactos, como o Pacto Global (1999), tenham um objetivo velado, conforme citado a seguir:

O verdadeiro objetivo já havia sido alcançado: vender a ideia de que existe um capitalismo como rosto humano ("cara humana ao mercado global") e que ele está sendo implementado via projetos de Responsabilidade Social Corporativa - mas jamais por regulações estatais, internacionais ou populares sobre a atividade das empresas (PACS, 2015).

Assim, mesmo com a atuação das organizações internacionais há uma fragilização do espaço público que fica submetido ao capital global. Deve-se ressaltar, no entanto, que o papel das ETs no desenvolvimento é assunto controverso, pois refletem uma encruzilhada para

\footnotetext{
${ }^{11}$ Essa é uma questão que gera controvérsias. Até que ponto as empresas devem partilhar das responsabilidades do Estado é um dilema que permanece em aberto.

12 O Instituto Políticas Alternativas para o Cone Sul (Pacs) publica, em 2015, por exemplo, uma cartilha denominada "Responsabilidade social pra quê e pra quem? Análise crítica dos projetos de responsabilidade social corporativa da ThyssenKrupp Companhia Siderúrgica do Atlântico - TKCSA -, em Santa Cruz, Rio de Janeiro, Brasil”, em que tece crítica às falácias das ações realizadas sob o slogan da responsabilidade social, denunciando as violações cometidas pelas empresas ThyssenKrupp (alemã) e pela brasileira Vale S.A., na construção de uma siderúrgica na cidade de Santa Cruz no Rio de Janeiro.
} 
os países anfitriões: em uma vertente, danos, impactos sociais e, por vezes, violações aos direitos humanos; de outra, a aliança ou promessa de que as empresas irão contribuir para o progresso, a industrialização e fomentar as relações de consumo.

As construtoras brasileiras são exemplos desse processo. As transnacionais brasileiras, como Odebrecht, Andrade Gutierrez e o grupo Camargo Corrêa, promovem ações sociais e de sustentabilidade ditas indissociáveis das estratégias das empresas. A Odebrecht, por exemplo, fundada em 1944 e atuando no exterior desde $1979,{ }^{13}$ afirma que desde a sua origem os princípios decorrentes da sustentabilidade estão presentes. Para a Odebrecht, a sustentabilidade é um conceito complexo e multidimensional (abrange o econômico, o social, o político, o cultural e o ambiental) que vem se aprimorando com o passar dos anos. Por meio deste preceito, visa o desenvolvimento sustentável dos locais onde atua (https://www.odebrecht.com).

Lobo (2006) demonstra, contudo, que no final da década de 80 e início da de 90 do século 20 , a visão social das empresas no Brasil, dentre elas a Odebrecht, ${ }^{14}$ ainda estava permeada pela noção de filantropia empresarial. Em 1989 a construtora participa de um encontro sobre filantropia promovido pela Comunidade da Câmara de Comércio de São Paulo. O grupo, com encontros regulares informais, origina o Grupo de Institutos, Fundações e Empresas (Gife), em 1995, com o objetivo de orientar as ações sociais, aperfeiçoando as práticas e o uso dos recursos privados para o desenvolvimento de todos. No final da década de 90 , o termo empregado pelo Gife passa a ser investimento social privado, aproximando-se do conteúdo da RSC. Em artigo publicado em 2006, Candace Lessa, diretora do Programa Brasil do Instituto Synergos e Fernando Rosseti, secretário geral do Gife afirmam:

É necessária mais pesquisa para esclarecer a distinção entre filantropia/investimento social privado e responsabilidade social corporativa. Essa distinção não apenas definirá mais claramente as necessidades e o rumo do setor, mas também dará mais visibilidade a algumas das excelentes tecnologias sociais que foram desenvolvidas pelas organizações de origem empresarial (LESSA; ROSSETI, 2006).

A fala dos autores demonstra a ausência de clareza quanto ao alcance e significado das expressões. Quanto à Odebrecht, a partir de 1993 alguns fatos se destacam. Em 1993/1994, por exemplo, a empresa elabora o primeiro conjunto de diretrizes socioambientais que orientam o setor de Engenharia e Construção, e publica o seu primeiro Relatório de Responsabilidade Social. Na Organização Odebrecht a função política social pública, como apontado, delineia-se por meio da "Política de Sustentabilidade", na qual o conceito de desenvolvimento sustentável é incorporado ao caráter institucional da empresa, que afirma que sua política de sustentabilidade baseia-se em cinco diretrizes: promover o desenvolvimento econômico, promover o desenvolvimento social, agir com responsabilidade ambiental, incentivar a participação política ${ }^{15}$ e valorizar a cultura.

\footnotetext{
${ }^{13}$ A Odebrecht inicia a sua internacionalização na América do Sul construindo, em 1979, a hidrelétrica de Charcani V, em Arequipa, Peru. Em 2012, segundo ranking da Fundação Dom Cabral, era a construtora brasileira mais transnacionalizada por número de países em atuação (25 países).

${ }^{14}$ A autora cita outras empresas, como o Bradesco, a Ford e o Itaú Cultural dentre outras.

15 Incentivar a participação política, de acordo com a Odebrecht, refere-se a "articular os interesses dos cidadãos junto a governos e representantes da sociedade civil" (Odebrecht).
} 


\section{Humanos e}

Democracia

O debate sobre a RSC, no entanto, permanece. Em artigo escrito em 1997, Sergio Foguel, vice-presidente da Odebrecht S.A. e presidente da Fundação Odebrecht, faz a seguinte indagação: O que é uma empresa socialmente responsável? Para ele, não é aquela que somente cumpre as suas obrigações legais, como pagar tributos ou cumprir a legislação trabaIhista, ou seja, coaduna com o significado de que não basta cumprir a lei, conforme descrito pela ONU. O vice-presidente também discorda que seja função primordial da empresa apresentar soluções ao desenvolvimento do país. Certamente, Forguel faz a crítica afastando as ações empresariais da responsabilidade pública do Estado. Sucinta, neste caso, a difícil relação entre o privado e o público. Assim, quando o Balanço Social Ibase, lançado nos anos 90, apresenta como objetivo tornar pública e divulgar a responsabilidade social empresarial, diante das controvérsias sobre os indicadores, a defesa do representante da Odebrecht é que a responsabilidade principal da empresa é:

[...] prestar bons serviços e/ou fornecer produtos de qualidade, atendendo à legislação, sem gerar desperdícios ou prejudicar o meio ambiente. E se estão criando hoje as condições para continuar a fazê-lo no futuro: capacitando seus integrantes, promovendo progresso tecnológico e desenvolvimento. $O$ exercício dessa responsabilidade é que assegura a sobrevivência e o crescimento orgânico da empresa. Já o não-exercício competente desta responsabilidade pode levar a rupturas, inclusive situações falimentares danosas não somente para os empresários mas para toda a sociedade, pois geram inadimplência de compromissos com funcionários, clientes, fornecedores, etc. (FOGUEL, 1997).

Frisa-se que a RSC é aquela que combina com a "sobrevivência e crescimento orgânico da empresa". Dessa maneira, a interpretação do que é RSC, segundo Foguel, parte da empresa e não da população afetada. Nota-se que, neste discurso, a RSC não expressa uma parceria simétrica entre empresa e comunidade.

Desde 2006 a Odebrecht disponibiliza em sua plataforma on-line seus relatórios anuais. Nestes relatórios constam as atividades executadas sob o lema da responsabilidade social empresarial. No ano citado, consta que a empresa patrocinou 120 projetos sociais, investindo aproximadamente R\$ 29 milhões (ODEBRECHT, 2006/2007). Cinco anos depois, os números foram mais expressivos, aproximadamente 102 milhões de reais em programas sociais, ambientais e culturais. Foram 437 programas sociais, ambientais ou culturais realizados no Brasil e 164 no exterior. O investimento no Brasil foi de $R \$ 78,44$ milhões e no exterior de $R \$ 24,11$ milhões $^{16}$ (ODEBRECHT, 2011/2012). De acordo com a empresa, na análise de seus projetos é considerado o impacto positivo que pode ser gerado na vida da comunidade. Dessa forma, as práticas sustentáveis tornaram-se uma "exigência inegociável" (ODEBRECHT, 2011/2012).

Em suma, neste primeiro momento, sobre a atuação das ETs, a governança corporativa aparece como uma diretriz que fortalece a empresa no seu mercado e garante a sua credibilidade perante investidores e sociedade. A responsabilidade social das empresas, contudo, é marcada por ambiguidades. Apesar de vários projetos citados em seus Relatórios Anuais ou de Sustentabilidade, no caso das construtoras brasileiras (ODEBRECHT, 2017/2018; CAMARGO CORRÊA, 2014; ANDRADE GUTIERREZ, 2015), a contradição no processo de responsabilidade

\footnotetext{
${ }^{16}$ Investimentos no exterior transformados em R\$ pela cotação 1 US\$ = R\$ 1,8758 em 31 de dezembro de 2011 (Relatório Anual Odebrecht, 2011/2012).
} 
social é inerente. Da mesma forma que as ações sociais são divulgadas, não faltam exemplos de obras realizadas por estas construtoras que, em algum momento, são acusadas de infringir leis ambientais, de desconsiderar os impactos sociais, de desrespeitar os direitos humanos ou de realizar condutas ilícitas. As denúncias apuradas pela operação Lava Jato evidenciam os fatos. Lembra-se que Marcelo Odebrecht, presidente da Odebrecht, foi condenado, em 8 de março de 2016, pelo então juiz Sérgio Moro, a 19 anos e 4 meses de prisão por corrupção, lavagem de dinheiro e formação de organização criminosa.

Dessa forma, segundo Nasser e Bundini (2016), na década de 90, ainda que houvesse uma discussão sobre a influência dos atores não estatais no sistema internacional, o ponto analítico central era o da cooperação e não do conflito. A responsabilidade social aparece como medida compensatória para um prejuízo gerado. A preocupação é alinhar as atividades corporativas com os ditames do desenvolvimento. Na atualidade, o foco na assimetria entre os atores internacionais repercute em uma análise que frisa a produção sistêmica de injustiças. Assim, em um mundo de desigualdades crescentes, abre-se um lapso cada vez maior entre a força dos agentes econômicos e a capacidade de resistência ou reparação, no qual uma nova linguagem, na visão da sociedade civil, tornou-se necessária.

\section{A LINGUAGEM DOS DIREITOS HUMANOS E A EXPECTATIVA POR JUSTIÇA}

As contradições entre o discurso de responsabilidade social e a prática na atuação das empresas são recorrentes. Uma realidade complexa, que envolve interesses e diferentes visões de mundo. As diretrizes das normas de RSC não se mostraram suficientes diante das expectativas sociais. Para além, ao postular a problemática na esfera dos direitos humanos, indica-se o reconhecimento de que as corporações são atores internacionais que dispõem de tanto poder quanto possibilidade de infringir as prerrogativas de tais direitos, assim como os Estados. Segundo Ruggie (2014),

O discurso dos direitos humanos - que afirma o valor e a dignidade inerentes a todas as pessoas, em todos os lugares - tornou-se um terreno comum com base no qual começaram a questionar e buscar um ressarcimento para os custos humanos da globalização corporativa (e-book).

A proposta de um tratado vinculante ${ }^{17}$ fundamenta-se no questionamento da assimetria entre as empresas, os Estados e os povos e no objetivo de pôr fim ao processo de impunidade com relação ao poder corporativo.

O debate sobre a conduta das ETs pelo prisma dos direitos humanos, intensifica-se em agosto de 2003, quando a Comissão de Direitos Humanos da ONU apresenta o texto "Responsabilidades das Corporações Transnacionais e Outras Empresas de Negócios com relação a Direitos Humanos" (CHR, 2003). Em 2005, o Conselho de Direitos Humanos da ONU decide compreender melhor a relação entre as transnacionais e os direitos humanos. A decisão presente no documento "Human rights and transnational corporations and other business enterprises", parte do pressuposto de que as transnacionais podem colaborar com os preceitos dos direitos humanos se considerados fatores como investimentos realizados, criação

\footnotetext{
17 Normas jurídicas internacionais de caráter obrigatório.
} 


\section{Humanos e}

Democracia

de empregos e estímulo ao crescimento econômico. Por outro lado, indica que se considere um funcionamento responsável das empresas e uma legislação nacional efetiva. Com esse diagnóstico inicial e na ausência de demais informações, propõe que seja realizado um trabalho (via mecanismos de consultas e recomendações), durante o período de dois anos, que elucide questões como: Quais são as normas sobre a responsabilidade das transnacionais na esfera dos direitos humanos? Qual a função de regulação dos Estados? Quais as implicações de conceitos como "cumplicidade" e "esfera de influência"?, bem como elabore metodologias de avaliação dos impactos da atuação das transnacionais e descreva as melhores práticas realizadas (CHR, 2005).

Como resultado da série de consultas formuladas sobre as normas e práticas existentes e os abusos em direitos humanos, em 2011 a ONU aprovou os Princípios Orientadores sobre Empresas e Direitos Humanos (Princípio de Ruggie). O documento é composto de 31 princípios de atuação quanto às responsabilidades dos Estados e das empresas em respeitar os direitos humanos e sobre o acesso aos mecanismos de reparação (HRC, 2011a). A Proposta de Ruggie é baseada em três pilares: Proteger (proteção dos Estados); Respeitar (respeito provido pelas empresas) e Reparação (mecanismos de indenização das vítimas), formando uma possibilidade maior de empoderamento. No que se refere às empresas, a proposta envolve um processo de auditoria que previna, avalie os impactos em direitos humanos e proponha mecanismos alternativos de solução dos conflitos.

Os Princípios de Ruggie circunscrevem um avanço na problemática, uma vez que é um guia oficial sobre como deve ser o vínculo entre a atividade empresarial e os direitos humanos. Ainda, contudo, não é a resposta esperada para frear as atitudes negativas das corporações. Sendo de caráter voluntário, da mesma forma que as normas de RSC, permanece a insegurança. Isto significa que não possui mecanismo para conferir autoridade ou procedimentos coercitivos ou de reparação quando não se age em conformidade com os preceitos aferidos. Não ter um caráter vinculativo, todavia, foi o que possibilitou a sua aprovação, afirma Ruggie, o condutor e formulador da proposta (RUGGIE, 2014).

Vislumbra-se, assim, que os direitos humanos foram incorporados como linguagem de reivindicação e passou-se a uma compreensão ampliada de seu significado. Não houve, no entanto, uma mudança capaz de frear a impunidade. Dessa maneira, em 2012, na Cúpula dos Povos Rio +20, foi lançada a "Campanha Global para desmantelar o poder corporativo". A campanha reuniu aproximadamente 200 atores entre movimentos sociais, organizações não governamentais e sindicatos, ${ }^{18}$ com o objetivo de denunciar as violações dos direitos humanos e protagonizar uma discussão sobre os meios efetivos de combate à impunidade das corporações (TRATADOS DOS POVOS, 2014). A pressão exercida por tal esforço resultou na abertura do processo formal de discussão do tratado vinculante na ONU.

Dessa forma, na 26a sessão do Conselho de Direitos Humanos, o Equador e a África do Sul, juntamente com 80 países, apresentaram a proposta de criar um quadro jurídico vinculante. Neste caso, a Resolução 26/9 de 2014 decide:

\footnotetext{
${ }^{18}$ Os signatários estão elencados no site da Campanha Dismantle Corporate Power. Disponível em: https://www. stopcorporateimpunity.org/lista-de-signatarios-2/?lang=pt-br. Acesso em: 28 mar. 2018.
} 
[...] estabelecer um grupo de trabalho intergovernamental de composição aberta sobre empresas transnacionais e outras empresas com relação aos direitos humanos, cujo mandato será desenvolver um instrumento juridicamente vinculante para regulamentar as atividades de empresas transnacionais e outras empresas no direito internacional de direitos humanos ${ }^{19}$ (tradução nossa) (HRC, 2014, p. 2).

Esta resolução pode ser considerada uma ruptura com relação aos debates anteriores envolvendo as transnacionais, o desenvolvimento, a responsabilidade social e os direitos humanos. O fato de elucidar as lacunas pelas quais as transnacionais desvinculam-se de suas obrigações, indica uma proposta de reformulação no direito internacional. Um dos pontos-chave, segundo Garcés (2017), é ilustrar como as vítimas de direitos humanos podem ter a garantia do acesso à justiça. Na atualidade há uma série de interpretações sobre jurisdição e ausência de um tribunal internacional, no qual as vítimas poderiam recorrer. Neste sentido, ocorre um vácuo normativo que tem beneficiado os interesses das corporações. A Campanha "Desmantelar o Poder Corporativo" tem como uma de suas proposições a criação de um Tribunal Internacional sobre empresas transnacionais (TRATADO DOS POVOS, 2014).

Na votação para aprovar a resolução 26/9, dos 47 votos 20 foram a favor, 14 contra e 13 foram abstenções. Dos países da América do Sul abstiveram-se, juntamente com o Brasil, a Argentina, o Chile e o Peru. Países como os Estados Unidos, Alemanha, Itália, França e Reino Unido, votaram contra. Por outro lado, Rússia e China votaram a favor (HRC, 2014). Como se pode notar, trata-se de um processo de enfrentamento de interesses políticos e econômicos. Os Estados, certamente, refletem não somente sobre os impactos negativos sofridos em seus territórios pela presença das ETs, mas, também, como as suas respectivas empresas seriam demandadas juridicamente no âmbito internacional.

As violações em direitos humanos por parte das transnacionais são tão mais recorrentes quanto maior a fragilidade dos Estados e a vulnerabilidade jurídica da população afetada (RUGGIE, 2014). As discussões na ONU, todavia, frisam a responsabilidade dos Estados em controlar e fiscalizar a conduta das empresas. A necessidade de um tratado internacional vinculante de responsabilização é uma forma de enfrentamento de interesses políticos e econômicos, e indica, ao mesmo tempo, a força e a fragilidade da organização internacional. A Organização das Nações Unidas coloca-se como uma fonte importante de pressão social internacional, mas, por outro lado, seu embate é um processo moroso que lida com resistências diversas.

O Grupo de Trabalho da ONU sobre direitos humanos e transnacionais, em visita ao Brasil em 2016, em seu relatório ilustra a problemática no caso brasileiro. No caso do Brasil, a comissão apontou como as violações têm impactado a vida das pessoas e a necessidade de avanços na relação Estado-empresa. Uma das questões destacadas no relatório é a existência de dúvidas sobre o que significa proteção dos direitos humanos no âmbito empresarial. Como

\footnotetext{
19 "Decides to establish an open-ended intergovernmental working group on transnational corporations and other business enterprises with respect to human rights; whose mandate shall be to elaborate an international legally binding instrument to regulate, in international human rights law, the activities of transnational corporations and other business enterprises" (HRC, 2014, p. 2).
} 


\section{Humanos e}

Democracia

visto anteriormente, quando do surgimento das normas de RSC também ocorreram incertezas quanto ao seu conteúdo. Assim, segundo o relatório, a relação entre direitos humanos e transnacionais ainda preceitua esclarecimentos:

O Grupo de Trabalho observou que os riscos de direitos humanos eram vistos principalmente como sendo riscos às operações de uma empresa, em vez de riscos enfrentados por detentores de direitos vulneráveis. As empresas não devem apenas avaliar o risco dos direitos humanos analisando o risco para a empresa do sucesso ou fracasso de seus projetos $^{20}$ (tradução nossa) (HRC, 2016, p. 5).

De acordo com o relatório, na complexidade das relações corporativas, a linguagem dos direitos humanos atenta-se para os potenciais riscos aos vulneráveis. No mais, há a constatação do grupo de trabalho de que a visão errônea das empresas sobre os direitos humanos na esfera corporativa pode ser em consequência da menor familiaridade das empresas sobre o significado dos direitos humanos, se comparadas com o Estado e a sociedade civil (HRC, 2016).

Ainda quanto às violações de direitos humanos no Brasil, para compreender a situação do país o grupo de trabalho dialoga com as comunidades afetadas, em especial, por três empreendimentos: a usina de Belo Monte, a barragem de Fundão (desastre do Rio Doce ou desastre de Mariana) e as construções para as Olimpíadas de 2016, principalmente nas cidades de São Paulo, Rio de Janeiro e Belo Horizonte. Os três casos citados são amostras de uma perspectiva rotineira de violações que implicam deslocamentos forçados, dificuldade de acesso à justiça, desrespeito às normas ambientais e trabalhistas, dentre outras.

Sobre a construção de hidrelétricas por empresas brasileiras aliadas a empresas estrangeiras, como nos casos de Belo Monte (Pará), Jirau (Rondônia) e Santo Antônio (Rondônia), as denúncias sobre direitos humanos são recorrentes. A UHE Santo Antônio, por exemplo, é administrada pela empresa Santo Antônio Energia (SAE), que tem como uma das acionistas a empresa Odebrecht com 18,5\% das ações (SAE, 2018). Segundo o relatório da Plataforma Dhesca Brasil, ${ }^{21}$ produzido em 2011, durante a construção da referida usina constatou-se diversas violações de direitos humanos, como desrespeito à legislação trabalhista, relatando-se que o Ministério Público ajuizou ação contra a obra em razão do "acentuado grau de negligência" (DHESCA BRASIL, 2011).

\footnotetext{
20 "The Working Group noted that human rights risks were mainly seen as risks to a company's operations, rather than risks faced by vulnerable rights holders. Companies should not just be assessing human rights risk by analysing the risk to the company of the success or failure of projects". (HRC, 2016, p.5)

${ }^{21}$ A DhESCA Brasil é uma "rede nacional de articulação de organizações da sociedade civil que visa promover os Direitos Humanos econômicos, sociais, culturais e ambientais como direitos humanos em seu conjunto universais, indivisíveis e interdependentes, articulados ao aprofundamento e radicalização da democracia e a construção de um modelo de desenvolvimento sustentável e solidário" (Disponível em: https://www.plataformadh.org.br/).
} 
No caso de Belo Monte, apesar de a Odebrecht ter desistido de participar do leilão ocorrido em 20 de abril 2010, ${ }^{22}$ posteriormente, em agosto de mesmo ano, em acordo com o governo, decidiu participar do processo de construção que foi liderado pela empresa Andrade Gutierrez. ${ }^{23}$ Já em 2011, as comunidades indígenas e ribeirinhas do Xingu apresentaram denúncia contra o Brasil na Comissão Interamericana de Direitos Humanos (CIDH) em razão dos impactos da construção na vida da comunidade indígena e ribeirinha. A apresentação do caso à CIDH ocorreu depois de visualizar, no sistema nacional, um emaranhando jurídico que, aliada à pressão do governo brasileiro pela construção da obra, impedia o acesso à justiça por parte dos afetados (SALES, 2017).

No tocante às obras para a Copa do Mundo e Olimpíadas no Brasil, somente a título de ilustração, vale ressaltar as acusações feitas às principais empresas brasileiras de construção (Odebrecht, Andrade Gutierrez, Camargo Corrêa, Queiroz Galvão e OAS) quanto às irregularidades na licitação e desrespeito aos direitos humanos nas obras dos eventos citados. No dossiê "Megaeventos e Violações dos Direitos Humanos no Rio de Janeiro", constam questionamentos sobre irregularidades ambientais, ausência de transparência dos recursos públicos, desrespeito aos direitos da população removida ou atingida pelas obras e outras violações (COMITÊ POPULAR DA COPA E OLIMPÍADAS DO RIO DE JANEIRO, 2014). Segundo Esposito (2017), somente na reforma do Maracanã a Odebrecht pagou próximo a $R \$$ 7,3 milhões em propinas.

Nas obras realizadas no exterior, o modus operandi repete-se. Em 12 países, a Odebrecht e a Braskem admitiram o pagamento de, aproximadamente, US\$ 1 bilhão em propinas no total (MATOSO; SALOMÃO, 2016). A confissão consta no acordo de leniência com o Departamento de Justiça dos Estados Unidos, realizado em dezembro de 2016 (BARROCAL, 2017).

Em 31 de julho de 2018, contudo, a Odebrecht S.A., juntamente com outras empresas do Grupo, firmou a "Carta Compromisso do Movimento Empresarial pela Integridade e Transparência", com a promessa de fortalecer o combate à corrupção. O documento é uma iniciativa do Instituto Ethos ${ }^{24}$ em parceria com o Pacto Global das Nações Unidas e da Transparência Internacional Brasil, que tem o objetivo de "sensibilizar e ajudar as empresas a gerir seus negócios de forma socialmente responsável" (ETHOS, 2019).

Diante de diretrizes, normas e monitoramento por organizações internacionais, por que não é possível impedir a violação sistemática dos direitos humanos? A hipótese principal é que as transnacionais conseguem organizar o sistema político e jurídico em favor de seus interesses. Assim, Maso (2017) tece considerações sobre o poder de influência das transnacionais

\footnotetext{
${ }^{22}$ O leilão foi vencido pelo consórcio Norte Energia com a seguinte composição: Chesf (Companhia Hidroelétrica do São Francisco), com 49,98\%; Construtora Queiroz Galvão S.A., com 10,02\%; Galvão Engenharia S.A., com 3,75\%; Mendes Junior Trading Engenharia S.A., com 3,75\%; Serveng-Civilsan S.A., com 3,75\%; J Malucelli Construtora de Obras S.A., com 9,98\%; Contern Construções e Comércio Ltda., com 3,75\%; Cetenco Engenharia S.A. com 5\%; Gaia Energia e Participações, com $10,02 \%$.

${ }^{23}$ Onze construtoras integraram o grupo, no entanto Odebrecht, Camargo Corrêa e Andrade Gutierrez ficaram responsáveis por $50 \%$ da obra.

${ }^{24}$ Trata-se de uma Organização da sociedade civil de interesse público.
} 


\section{Humanos e}

Democracia

e aponta para a existência de um lobby das empresas no processo de tomadas de decisão, seja no financiamento de especialistas para legitimar suas ações, seja no financiamento de campanhas eleitorais e eventos ou na participação formal em agências reguladoras.

Nasser e Bundini (2016) relatam o que tem se denominado de "arquitetura da impunidade". Segundo os autores, trata-se da construção de uma relação entre os Estados e as empresas, que abarca

um quadro jurídico abrangente e vinculativo de comércio e investimentos por meio de tratados e acordos, incluindo resoluções de instituições internacionais - como a Organização Mundial do Comércio, o Banco Mundial e o Fundo Monetário Internacional - e mecanismos de solução de controvérsias investidor-Estado (p. 208).

Nessa complexidade dessas relações, configura-se o poder das transnacionais em deter prerrogativas quanto aos seus interesses. Nestes termos, as corporações conseguem facilitar operações, manipular legislações e legitimar contratos. Um dos pressupostos é que as transnacionais, pelo seu poder econômico e flexibilidade de atuação, têm promovido uma privatização da justiça dificultando que a população possa ter mecanismos eficazes de promoção de seus direitos. Ao lado do termo arquitetura da impunidade, coloca-se outro que é o da segurança jurídica. Para Zubizarreta (2017), no momento em que os contratos determinam a plena segurança dos investimentos realizados pelas corporações, em consequência estabelecem uma hierarquia entre o aspecto econômico de proteção dos contratos e a defesa dos direitos humanos. Como não há um instrumento efetivo de proteção aos direitos humanos em âmbito internacional, os Estados e a população encontram-se vulneráveis perante o poder corporativo.

Na visão da filósofa Nancy Fraser, a globalização modifica a forma como se discute justiça, pois, antes, qualquer que fosse a reivindicação, a unidade que amparava a busca pela justiça era o Estado Nacional. Com as forças transnacionais (da qual as ETs são exemplo) percebe-se um novo tipo de vulnerabilidade, pois os processos que as compõem formam-se ultrapassando fronteiras (FRASER, 2009). Neste momento, tem-se a necessidade de transformar as lutas locais em lutas internacionais, desmantelando obstáculos institucionalizados nacionalmente e que impedem a participação igualitária no sistema de justiça dos Estados. Para a autora, no âmbito do Estado nacional pode ocorrer uma falsa representação, ou seja, afirma-se a possibilidade de representação, mas criam-se fronteiras dentro do político que excluem os indivíduos de participarem dos debates sobre justiça. Assim, Fraser (2009) assevera:

Cada vez mais sujeito à contestação, o enquadramento Keynesiano-Westfaliano é agora considerado, por muitos, um grande produtor de injustiça, já que ele fraciona o espaço político de tal modo que impede os pobres e os desprezados de desafiarem as forças que os oprimem. Ao direcionar as reivindicações para os espaços políticos domésticos dos relativamente desempoderados, senão totalmente falidos, Estados nacionais, esse enquadramento isola, da crítica e do controle, os poderes que estão fora dos limites nacionais. Entre aqueles protegidos do alcance da justiça estão os Estados predadores mais poderosos e os poderes privados transnacionais, inclusive investidores e credores estrangeiros, especuladores monetários internacionais e corporações transnacionais (p. 23). 
Nesta lógica, a reinvindicação em organizações internacionais para a reformulação do direito internacional tende a ser a alternativa mais plausível teoricamente, ainda que desafiadora na prática. A Resolução 26/9 é uma luta nesta direção.

Por fim, frisa-se a diversidade da conjuntura mundial e das demandas entre a década de 90 e nos anos 2000. Como visto, a RSC é uma fonte de adesão voluntária, um compromisso que visa à ética empresarial baseada na compreensão do mercado sobre a sua função social. Já a demanda por respeito aos direitos humanos e a relação com as transnacionais, insere a necessidade de normas obrigatórias com um aparato jurídico e mecanismos que facilitem o acesso à justiça, ou seja, uma regulação efetiva das ações das transnacionais.

Destarte, amplia a visão sobre os direitos e os reúne em uma única causa - os direitos humanos. A proposta rediscute a dependência do direito nacional e propõe uma normatização internacional, reformulando o direito internacional. Se a RSC propõe padronizar e direcionar a conduta empresarial, o foco da discussão sobre os direitos humanos e transnacionais visa a impedir a impunidade. Situa-se em confronto o direito econômico e comercial com os direitos humanos, preconizando uma reformulação normativa e das instituições.

\section{CONSIDERAÇÕES FINAIS}

O que fazer quando o sistema de governança aparece em uma encruzilhada? Nota-se que a participação das empresas transnacionais na governança global estabelece uma difícil relação entre o público e privado e entre as esferas da economia e do social. Traduz-se em uma relação de força em que grupos são vulnerabilizados. Na balança entre os danos causados à população, de um lado, e a realização de medidas compensatórias, de outro, reside uma falácia sobre a noção de justiça.

As ETs possuem grande capacidade de manobra. Sua capacidade de influenciar a política é reconhecida. O discurso da responsabilidade social não foi suficiente para conciliar os interesses das corporações privadas e os interesses da sociedade, causando uma descrença social quanto à possibilidade de unir lucro e responsabilidade voluntária ao bem-estar social. Assim, a RSC é analisada, em essência, como um discurso que visa a garantir a sobrevivência em um mercado competitivo, fortalecendo a identidade da empresa com seus consumidores e acionistas. Revela, tão somente, ações pontuais e fragmentadas baseadas em decisões unilaterais que tornam o processo duvidoso.

Um tratado internacional vinculante seria uma proposta revolucionária no direito internacional. O poder de punir, assim, aparece como o caminho efetivo. É, no entanto, uma direção de solução tão difícil quanto a que prescreve a prevenção e mudança de cultura empresarial. Permanece no sistema nacional e internacional o entendimento de que, independente da capacidade de ação da empresa, é de responsabilidade do Estado nacional direcionar e garantir suas vontades e interesses. Cabe ao Estado, como poder soberano, criar mecanismos de contrapoder atribuindo às empresas uma função condizente com o interesse público legítimo. Os governos nacionais devem desenvolver uma legislação forte aliada a mecanismos internacionais para impor responsabilidades às empresas transnacionais e manter a soberania do Estado. Neste sentido, não há alternativa no cenário internacional. 


\section{Humanos e}

Democracia

Diante da perspectiva do lucro, ambos (prevenir e capacidade de punir) surgem como medidas de longo prazo. No mais, deve-se recordar que os direitos humanos atuam como um guia para os desejos da humanidade (SEN, 2006). As discussões na ONU transitam entre uma política legítima de caráter voluntário e uma obrigatoriedade jurídica, primando, de qualquer forma, por um sistema de governança com a participação e a fiscalização de diversas organizações, instituições e Estados.

Em suma, apesar das transformações no debate, as diretrizes são insuficientes para frear a impunidade e converter a fragilidade jurídica da população ante o poder corporativo. Os anseios da sociedade estão expostos, mas os sistemas de justiça operam em lógicas distintas e oferecem resistência.

\section{REFERÊNCIAS}

ANDRADE GUTIERREZ. Grupo Andrade Gutierrez - Relatório de Sustentabilidade 2015. Disponível em: http:// www.andradegutierrez.com/ComoFazemos.aspx. Acesso em: 28 abr. 2018.

BARROCAL, A. Delação da Odebrecht nos Estados Unidos sacode a América Latina. Carta Capital, 4/2/2017. Disponível em: https://www.cartacapital.com.br/internacional/delacao-da-odebrecht-nos-eua-sacode-a-america-latina. Acesso em: 19 maio 2017.

BEZERRA, R. B. Responsabilidade social corporativa: uma proposta metodológica para orientação de iniciativas. 2007. Dissertação (Mestrado em Ciência em Planejamento Energético) - Universidade Federal do Rio de Janeiro, Programas de Pós-Graduação de Engenharia Rio de Janeiro, mar. 2007. Disponível em: http://www.ppe.ufrj.br/ ppe/production/tesis/mbezerrarb.pdf. Acesso em: 26 abr. 2018.

CAMARGO CORRÊA. Relatório Anual 2014. Disponível em: http://camargocorrea.com.br/component/docman/ cat_view/1-relatorios-anuais?ltemid=. Acesso em: 28 abr. 2018.

CAVES, R. E. The Multinational Enterprise as an Economic Organization. In: FRIEDEN; Lake. International Political Economy - perspectives on global Power and wealth. St. Martin's Press New York, 1995.

CHR. Commission on Human Rights. E/CN.4/RES/2005/69. Human rights and transnational corporations and other business enterprises SRSG mandate. 20/5/2005.

CHR. Commission on Human Rights. E/CN.4/Sub.2/2003/L.11. Proyecto de Programa Provisional y Aprobacion del Informe - Proyecto de informe de la Subcomisión de Promoción y Protección de los Derechos Humanos. 14/8/2003.

COMITÊ POPULAR DA COPA E OLIMPÍADAS DO RIO DE JANEIRO. Megaeventos e Violações dos Direitos Humanos no Rio de Janeiro - Dossiê do Comitê Popular da Copa e Olimpíadas do Rio de Janeiro. Jun. 2014. Disponível em: http://www.childrenwin.org/wp-content/uploads/2015/12/Dossie-Comit\%C3\%AA-Rio2015_low.pdf. Acesso em: 10 ago. 2017.

DHESCA BRASIL. Violações de Direitos Humanos nas Hidrelétricas do rio Madeira - Relatório Preliminar de Missão de Monitoramento. Relatoria Nacional para o Direito Humano ao Meio Ambiente Plataforma Dhesca Brasil. Abril, 2011. Disponível em: http://www.global.org.br/wp-content/uploads/2016/03/r_dhescas_missao_rio_madeira.pdf. Acesso em: 10 jun. 2018.

DOS SANTOS, T. A teoria da dependência: balanço e perspectivas. Rio de Janeiro: Civilização Brasileira, 2000.

DUNNING, J. H. Reappraising the eclectic paradigm in an age of alliance capitalism. Journal of International Business Studies, v. 26, n. 3, 1995.

DUNNING, J. H.; ZHANG, F. Foreign direct investment and the locational competitiveness of countries. Transnational Corporations, v. 17, n. 3, 10 dez. 2008

ESPOSITO, I. R. Odebrecht pagou R\$ 7,3 milhões em propina por reforma do Maracanã. Agência Brasil, 18/4/2017. Disponível em: http://agenciabrasil.ebc.com.br/politica/noticia/2017-04/odebrecht-pagou-r-73-milhoes-em-propina-por-reforma-do-maracana. Acesso em: 5 abr. 2019.

ETHOS. Instituto Ethos. Disponível em: https://www.ethos.org.br/conteudo/sobre-o-instituto/\#.XNCW2GeG_IU. Acesso em: 5 abr. 2019.

FEENEY, P. A luta por responsabilidade das empresas no âmbito das Nações Unidas e o futuro da Agenda de Advocacy. SUR - Revista Internacional de Direitos Humanos, v. 6, n. 11, p. 175-191, dez. 2009. 
FOGUEL, S. Balanço social: a essência e a benemerência. Folha de São Paulo, São Paulo, segunda, 23 de junho de 1997. Disponível em: https://www1.folha.uol.com.br/fsp/dinheiro/fi230607.htm. Acesso em: 12 jan. 2019.

FRASER, N. Nancy Fraser: reenquadrando a Justiça em um mundo globalizado. Lua Nova, São Paulo, 77, p. 11-39, 2009.

GARCÉS, M. F. E. Nações Unidas: as transnacionais e os Direitos Humanos. In: Transnacionais e Direitos Humanos. América Latina, 520, Ed. português, jan. 2017.

GEORGE, A. L.; BENNETT, A. Case Studies and Theory Development in the Social Sciences. Cambridge, Massachusetts, Belfer Center for Science and International Affairs, 2004.

GILPIN, R. US power and the multinational corporation: The political economy of foreign direct investment. New York: Basic, 1975. 291 p.

HRC. Human Rights Council. A/HRC/17/31. Informe del Representante Especial del Secretario General para la cuestión de los derechos humanos y las empresas transnacionales y otras empresas, John Ruggie. 21/3/2011a.

HRC. Human Rights Council. A/HRC/32/45/Add.1. Informe del Grupo de Trabajo sobre la cuestión de los derechos humanos y las empresas transnacionales y otras empresas acerca de su misión al Brasil. 12/5/2016.

HRC. Human Rights Council. A/HRC/RES/17/4. Human rights and transnational corporations and other business enterprises. 6/7/2011b.

HRC. Human Rights Council. A/HRC/RES/26/9. Elaboración de un instrumento internacional jurídicamente vinculante sobre las empresas transnacionales y otras empresas con respecto a los derechos humanos. 26/6/2014.

HRC. Human Rights Council. A/HRC/RES/37/67. Report on the third session of the open-ended intergovernmental working group on transnational corporations and other business enterprises with respect to human rights. 24/1/2018.

HYMER, S. Empresas multinacionais: a internacionalização do capital. Rio de Janeiro: Edições Graal, 1983.

LESSA, C.; ROSSETTI, F. Criando um setor mais diversificado. 9/1/2006. Disponível em: https://gife.org.br/o-futuro-da-filantropia-no-brasil/. Acesso em: 15 abr. 2019.

LILIENTHAL, D. E. The multinational corporation: a review of some problems and opportunities for business management in a period of world-wide economic change. New York, Development and Resources Corporation, 1960. LOBO, C. G. de A. Por que as empresas investem em responsabilidade social? 2006. Tese (Doutorado) - Universidade de Brasília/UnB, Departamento de Sociologia, Brasília, 2006.

MARINI, R. M. Dialética da dependência. In: TRASPADINI, Roberta; STEDILE, João Pedro. Ruy Mauro Marini - vida e obra. São Paulo: Expressão Popular, 1973-2005.

MASO, T. F. Da terra nascem as sementes, mas também os direitos. In: Transnacionais e Direitos Humanos. América Latina, 520, Ed. português, jan. 2017.

MERLE, M.. Sociologia das Relações Internacionais. Brasília: Editora UnB, 1981.

MATOSO, Filipe; SALOMÃO, Lucas. Odebrecht e Braskem admitem US\$ 1 bi em propina em 12 países, dizem EUA. G1, Globo, Brasília. 21/12/2016. Disponível em: https://g1.globo.com/politica/noticia/odebrecht-admite-us-788-milhoes-em-propina-em-12-paises-dizem-eua.ghtml. Acesso em: 2 nov. 2018.

NASSER, R.; BUNDINI, T. As corporações transnacionais, os arranjos de governança global e os direitos humanos. In: STEFANO, Daniela; MENDONÇA, Maria Luisa (org.). Direitos Humanos no Brasil 2016. Relatório da Rede de Justiça e Direitos Humanos. 1. ed. São Paulo: Outras Expressões, 2016.

OCDE. Organização para Cooperação e Desenvolvimento Econômico. OCDE Guidelines for Multinational Entreprises. 2008. Disponível em: http://www.oecd.org/investment/guidelinesformultinationalenterprises/1922428.pdf. Acesso em: 12 jan. 2018.

ODEBRECHT. Relatório Anual 2006/2007. Disponível em: https://www.odebrecht.com/sites/default/files/port_ ra_impressao_05_jun_2007.pdf. Acesso em: 28 abr. 2018.

ODEBRECHT. Relatório Anual 2011/2012. Disponível em: https://www.odebrecht.com/sites/default/files/relatorio_anual_2012_portugues_0.pdf. Acesso em: 28 abr. 2018.

ODEBRECHT. Relatório Anual 2017/2018. Disponível em: http://relatorioanual.odebrecht.com/pdf_completo_ ra2017/ra_odebrecht_2017_pt.pdf. Acesso em: 28 abr. 2018.

OHCHR. United Nations Human Rights Council. Disponível em: http://www.ohchr.org/EN/HRBodies/HRC/WGTransCorp/Pages/IGWGOnTNC.aspx. Acesso em: 15 jan. 2018.

PACS. Instituto Políticas Alternativas para o Cone Sul. Responsabilidade social pra quê e pra quem? Análise crítica dos projetos de responsabilidade social corporativa da Thyssen Krupp Companhia Siderúrgica do Atlântico - TKCSA, em Santa Cruz, Rio de Janeiro, Brasil. Rio de Janeiro: Pacs. 1. ed. mar. 2015. 


\section{Humanos e \\ Democracia}

PELIANO, A. M. T. M. (coord.). Bondade ou interesse? Como e por que as empresas atuam na área social. Brasília: Ipea, 2001.

PREBISCH, R. Dinâmica do desenvolvimento latino-americano. Rio de Janeiro: Fundo de Cultura, 1964. 206 p.

RUGGIE, J. G. Quando negócios não são apenas negócios. As corporações multinacionais e os direitos humanos. Planeta Sustentável, São Paulo, 2014. Edição do Kindle.

SAE. Santo Antônio Energia. Em ritmo acelerado. Notícias. 27/11/2012. Disponível em: https://www.santoantonioenergia.com.br/em-ritmo-acelerado/. Acesso em 7 jun. 2018.

SALES, R. C. Belo Monte: cristalização do retrocesso ambiental e de direitos humanos. Justificando, 13 jun. 2017. Disponível em: http://www.justificando.com/2017/06/13/belo-monte-cristalizacao-do-retrocesso-ambiental-e-de-direitos-humanos/. Acesso em: 15 mar. 2019.

SEN, A. Human rights and the limits of law. Cardozo Law Review, 27, n. 6, 2006.

STRANGE, S. States and Markets - an introduction to international political economy. New York: B. Blackwell, 1988. 263p.

TRATADOS DOS POVOS. Ideias e propostas para avançar em direção a um Tratado Internacional dos Povos para o Controle das Empresas Transnacionais. Rebrip. Tradução Action Aid Brasil. Dez. 2014. Disponível em: https://www.stopcorporateimpunity.org/tratado-dos-povos/?lang=pt-br. Acesso em: 15 jan. 2018.

UNCTAD. The Social Responsibility of Transnational Corporations. New York and Geneva, 1999.

UNCTAD. World Investment Report 2012: Towards a New Generation of Investment Policies. 2012. Disponível em: https://unctad.org/en/PublicationChapters/WIR2012MethodologicalNote_en.pdf. Acesso em 20 jun. 2014. VELOSO, L. H. R. Responsabilidade social e globalização: redefinindo o papel das empresas transnacionais no Brasil. Antropolítica: Revista Contemporânea de Antropologia e Ciência Política, Niterói: EdUFF, n. 18, 1. sem. 2005. VERNON, R. Tempestade sobre as multinacionais. São Paulo: Zahar Editores, 1980.

ZUBIZARRETA. Um tribunal internacional para assegurar justiça às comunidades. In: Transnacionais e Direitos Humanos. América Latina, 520, Ed. português, jan. 2017. 